\title{
Devlet Tiyatroları İzmir-Konak Sahnesi'nin Akustik Özellikleri
}

\author{
Serhat DURMAZ *
}

Özet

Konser salonlarının akustik kalitelerini belirlemek amacıyla, Dokuz Eylül Üniversitesi BAP Koordinasyon Birimi'nce desteklenen ve on sekiz ay süren 'Konser Salonlarının Akustik Performanslarının Belirlenmesi' başlıklı araştırma projesi kapsamında, İzmir Büyükşehir Belediye sınırları içinde yer alan salonların akustik ölçümleri yapılmıştır. Bazıları tarihi eser sınıfına giren salonlardan biri de bu yazıya konu olan ve halen Devlet Tiyatroları tarafından kullanılan İzmir Konak Sahnesi'dir. Bu çalışmada, gerçekte tiyatro sahnesi olarak inşa edilmemiş olan salonun tiyatro etkinliklerinde nasıl bir performansa sahip olduğu araştırılmış ve olası akustik kusurları saptanmıştır. Analiz sonuçları doğrultusunda bu kusurların nasıl iyileştirilebileceği konusunda öneriler sunulmuştur.

Anahtar Sözcükler: Tiyatro akustiği, Mimari akustik, ISO 3382.

\section{Acoustical Characteristics of Izmir State Theatre - Konak Stage}

\section{Abstract}

In scope of the research project titled 'Defining Acoustical Performances of Concert Halls', which was supported by DEU BAP Coordination Unit and completed in eighteen months, the acoustical properties of concert halls within Izmir Metropolitan Municipality are measured to determine their acoustical quality. One of the halls that are acoustically measured in this project is Izmir State Theatre- Konak Stage; it is classified as a historical building.

In this paper, the probable acoustical defects and the kind of performance this concert hall can show in theatrical activities, which is in fact has not been bulit as a theatre stage, is investigated. According to the results, suggestions are made on how to consolidate these defects.

Keywords: Theater Acoustics, Architectural Acoustics, ISO 3382. 


\section{Giriş}

Nitelikli akustik özelliklerde sergi, konser salonu, tiyatro gibi sanatsal mekânların varlığı o toplumun kültür düzeyi, konforu, bireylerinin ruh ve beden sağlığı için önem taşır. Mevcut veya yeni yapılan kültürel mekânların doğru akustik özellikler ile donatılmış olması, sanat ve kültür etkinliklerinde kaliteyi artırıcı etkilere sahiptir.

Bu tür mekânların, sayıları kadar nitelikleri de önemlidir. Dünya genelinde son on yılda, oturma kapasitesi 1000 kişi ve üzerinde, akustik detayları önceden planlanmış iki yüz elliden fazla (örneğin Uzakdoğu'da 88 adet, Avrupa'da 69 adet, ABD'de 60 adet) modern konser salonu bulunur. Türkiye'de son on beş yılda inşa edilen Kültür Merkezi, Konser Salonu, Çok Amaçlı Salonlar vb. yapıların sayısı (45'i çok amaçlı olmak üzere) sadece 83’tür. Koltuk kapasitesi 750 kişiyi aşan tek salon ise Konya Mevlana Kültür Merkezi'dir (Kültür, 2015). İstanbul'da, son on yılda yapılan sadece üç konser salonu ve 100'e yakın çok amaçlı salon vardır ve büyük bir bölümü mimarların görüşlerine göre akustik açıdan uygun değildir (Türk, Can, Özçevik, 2011). İzmir'de toplam salon sayısı 40'a yakın olmakla birlikte sadece bir düzine kadar salon konser, tiyatro vb. profesyonel etkinliklere sahne açmaktadır.

Tasarım aşamasında akustik projesi bulunan salonların sayısı Türkiye genelinde 1 düzineyi, İzmir'de 1'i geçmez. Çoğunda akustiğin hiç dikkate alınmadığı, pek azında ise yetersiz ya da ilave önlemler ile alındığı bilinen bir gerçektir. Kötü haber, bunun kronik bir sorun olduğudur. İyi haber ise şudur ki, son beş yılda mimari projelerin artık akustik projeler ile birlikte değerlendirildiği, nitelikli akustik uzmanlarına duyulan ihtiyaçların giderek arttığıdır. Özel akustik projesi hazırlanmamış bir sahne sanatları mekânı ve/veya bir kültürel renovasyon projesi asla kabul edilemez.

Mevcut mekânlarımızın 'akustik kusur' kapsamına giren davranışlarını tespit etmek ve onları daha iyi hale getirmeye çalışmak, kültür düzeyimizi yükseltilmesine katkıda bulunmak adına iyi bir başlangıç olabilir. Bu açıdan bakıldığında, hangi akustik büyüklükleri öncelikli olarak dikkate almalıyız? Örneğin, tiyatro salonları gibi mekânlar konuşma ağırlıklı yerlerdir ve sahne diyaloglarının, repliklerin salonun her noktasından yeterli güç ve olabildiğince net biçimde algılanması beklenir. Uygun akustik değerleri sağlamayan tiyatro salonlarında dramatik mesajların algılanışı, oyuncu ile seyirci iletişimi ve dikkatleri olumsuz yönde etkilenir, hatta izleyiciler oyun sonunda kendilerini yorgun hissedebilir.

Salonlarda konuşmaların anlaşılırlığı, ses gücü düzeyleri, çınlamanın süresi, yanal enerji seviyeleri vb. önemlidir. Orta ölçekli tiyatro salonları için kabul gören bazı akustik değerler bulunur. Konuşmanın anlaşılırlığında hece boğumlanmaları önemlidir ve konuşmayı benzetleyen modülasyon transfer fonksiyonları ile ilişkilendirilir (Houtgast, Steeneken, 1985). STI bir "indeks" belirtir; bu 0 (en kötü) ile 1 (en iyi) arasında bir değer olabilir. Değerin 1'e yaklaşması konuşmaların kuru, cansız, dar bir ortamda duyulduğu anlamına gelir. Algılama açısından Belirginlik/Ayırt Edilebilirlik (Deutlichkeit, $D_{50}$ ) konuşma mekânlarının olmazsa olmazıdır (Thiele, 1953). Anlaşılırlığın ne durumda olduğu arka plan gürültü düzeyleri, çınlama süreleri, güç seviyeleri, erken düşme süreleri ile yakından ilgilidir. Bunlar seste dolgunluk, canlılık, parlaklık, hacim duygusu, uzaysal konum, kaynağa yakınlık vb. algıları için gereklidir. Bu nedenle gürültü düzeyi (2010c:tablo 9), Ses Gücü, G (Barron, 1993), Çınlama süresi, RT (Beranek, 1996), Erken Azalım Süresi, EDT (Gade, 1989) için kabul edilen sınır değerleri önemlidir. Bu çalışmada, bu parametreler için kabul edilen değerler şunlardır:

\begin{tabular}{|c|c|c|c|}
\hline Parametre adı & Sınır değerler & & Referans \\
\hline Erken azalım sūresi, EDT & $1,8-2,2$ & sn & (Barron, 2010) \\
\hline Cınlama süresi, RT & $0,7-1,0$ & sn & (Barron, 2010) \\
\hline Ses gūcū, G & $-2-10$ & $\mathrm{~dB}$ & (2010a:10)i \\
\hline Belirginlik, $\mathrm{D}_{50}$ & $0,3-0,7$ & - & (2010a:10) \\
\hline Ses iletim gästergesi, STI & $\begin{array}{l}0,45-0,60 \text { (kötü) } \\
0,60-0,75 \text { (iyi) } \\
0,75-1,00 \text { (mükemmel) }\end{array}$ & - & (Beranek, 1988) \\
\hline Arka plan gürūltū düzeyi & $>30\left(\mathrm{~L}_{\mathrm{N}}\right)$ & $\mathrm{dBA}$ & (2010c:tablo 9) \\
\hline
\end{tabular}

Tablo 1: Küçük-orta ölçek salonlar genel kabul değerleri

\section{Konak Sahnesi’nin Genel Mimari Özellikleri}

Bugün Devlet Tiyatroları İzmir Konak Sahnesi tarafından kullanılan yapı, mimar Necmettin Emre'nin projesiyle 1927 yılında tamamlandı. Önce Türk Ocağı, sonra halk eğitim merkezi olarak kullanıldı. Muhsin Ertuğrul'un çabaları ile 1957 yılında kurulan İzmir Devlet Tiyatrosu o yıldan sonra burada temsiller vermeye başladı (Oğuz, 2009). 2009 yılında bakım ve onarıma alınan binada çalışmalar 2010 
yılında tamamlandı. Çalışmalar sonunda tavan yüksekliği artırıldı, taban kotu 50 santim aşağıya çekildi, taşıyıcı yapıdan bağımsız bir sahne ve kulis yapıldı, kulis ve ışık odaları yenilendi (Yazıcı, 2010). Yenileme çalışmalarında akustik proje yoktu. Literatürde, akustik özellikleri, tiyatro sahnesine uygun olup olmadığı konusunda yayınlanmış bir çalışma veya onarım öncesi/sonrası akustiğine ilişkin herhangi bir bilgiye de rastlanmadı.

Bina gürültülü iki anayol, Mithatpaşa Caddesi ve Mustafa Kemal Sahil Bulvarı arasındaki arazide yer alır. Ön ve arka cepheden yoğun trafik akışının, sağ ve sol cepheden kafeterya kaynaklı çevresel gürültünün etkisi altındadır. Salonda iki giriş kapısı, yan duvarlarda ikişer adet çift kanatlı pencere, sahne yakınında iki adet tahliye kapısı bulunur. Kapılar yalıtımsız, pencereler kadife perde örtülü çift kanatlı ve tek katmanlı ahşap malzemedendir ve doğrudan avluya açılır. Zemin bitiş elemanı halıfleks, koltuklar polyester kumaş kaplı kontrplak karkaslı, yan duvarlar alçı sıva üzeri bezekli boyalı, tavan sıva kaplı, yüzey boyaları süslemeli havuz tip tavan sistemidir. Sahne tabanı ahşap lata, iç duvarları siyah fon perdesi ile kaplıdır. Zemin, sahne önünden başlayan aşamalı yükseltilmiş zemindir ve en arka sıranın altında oluşan kot farkı malzeme deposu olarak kullanılan zemin altı bölümünü oluşturur.

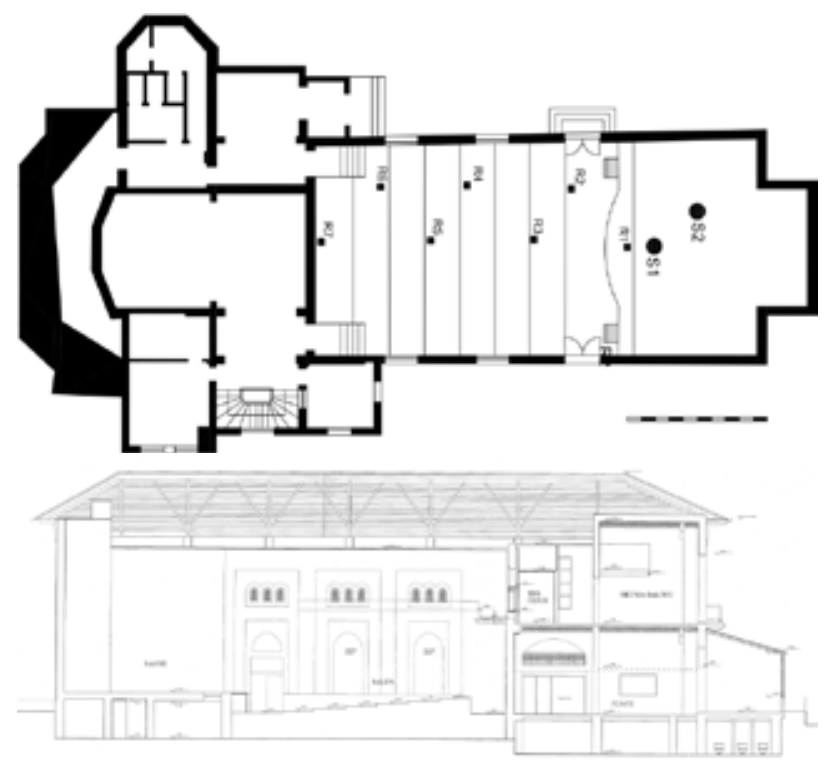

Şekil 1: İzmir Rölöve ve Anıtlar Müdürlüğü tarafından hazırlanan rölöve planı (üstte), kaynak (S1 ve S2) ve alıcı (R1-R7) noktaları, A-A kesiti (altta)
Sahnenin tam karşısında teknik ışık odası olarak kullanılan, ön kısmı tamamen salona açık bir balkon bulunur. Salon ile balkon arasında akustik engel yoktur ve ön cephesi tümüyle salona açıktır.

\begin{tabular}{lrllrl}
\hline Yükseklik (min - max) & $7,9-9,1$ & $\mathrm{~m}$ & Akustik oturma alanı & $124,8 \mathrm{~m}^{2}$ \\
\hline Genislik & 10,6 & $\mathrm{~m}$ & Fiziksel oturma alanı & $115,3 \mathrm{~m}^{2}$ \\
\hline Sahne & 83,8 & $\mathrm{~m}^{2}$ & Salon hacmi & $1513,3 \mathrm{~m}^{3}$ \\
\hline Salon (zemin) & 165,5 & $\mathrm{~m}^{2}$ & Sahne hacmi & $432,3 \mathrm{~m}^{3}$ \\
\hline Tavan & 197,2 & $\mathrm{~m}^{2}$ & Kontrol odası hacmi & $53,2 \mathrm{~m}^{3}$ \\
\hline Yan duvarlar & 297,2 & $\mathrm{~m}^{2}$ & Kişibaș hacim & $9,6 \mathrm{~m}^{3}$ \\
\hline Koltuk sayısı & 208 & adet & Kişi başı hacim (sadece salon) & $7,3 \mathrm{~m}^{3}$ \\
\hline
\end{tabular}

Tablo 2: Salonun fiziksel özellikleri

Kontrol odası bölümünün iki yanında iki küçük balkon sahne spotları için kullanılır. Tiyatro spotlarının diğer bölümü ışık köprüleri yardımı ile sahne yanı, sahne önü kare truss üstü, sahne iç yanları ve sahne tavanındaki demir kutu profillere asılıdır. Sahnenin iki yanındaki duvarlarda dört adet 15 inç iki yollu aktif seslendirme kabinleri, yan ve arka duvarlarda sekiz adet 8 inç sürücülü sinema tipi çevresel hoparlörler bulunur.

\section{ölçüm Prosedürü}

Akustik ölçümler 9 Şubat 2015 günü seyircisiz, boş salonda gerçekleştirildi. Çalışmalarda tamamı uluslar arası akustik standartları karşılayan Brüel \& Kjaer Type 4292L, Type 2734, Type 2250, Type 7841 (V6), $18 i 20$ mikrofon preamplifier, Dawe inst. Akustik kalibratör, nem, ısı, basınç ve uzaklıkölçer ile MacBook Pro ekipmanları kullanıld11).

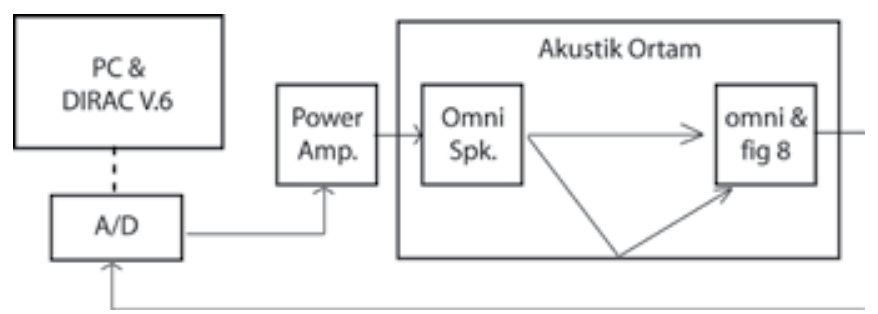

Şekil 2: Ölçme sistemi sinyal akış uygulama şeması

Konumları önceden hesaplanmış 2 kaynak (S1, S2) ve 7 farklı alıcı noktasında (R1-R7) akustik dürtü yanıtları kaydedildi, arka plan gürültü düzeyleri yönetmelikler ile belirlenen kurallar doğrultusunda tespit edildi (2010c: Ek. XVII); A ağırlıklı $\mathrm{L}_{\text {eq }}$ değerleri havalandırma sistem testleri için, HVAC açı//kapalı kullanım durumlarında ayrı-ayrı ölçümlendi. 
İlk alıcı kaynaktan $1 \mathrm{~m}$ uzağa, ikinci alıcı kaynaktan 10 m uzaklığa, sonrakiler aralarında en az 3'er m aralık olacak biçimde farklı konumlara yerleştirildi (2010b:4). Dodek ses kaynă̆ı sahnede iki farklı konumda kullanıldı. Böylece iki kaynak noktası ve yedişer alıcı noktası olmak üzere, tek uyaran için, 14 dürtü yanıtı ve yanal enerji kabulleri gerçekleştirildi. Üç farklı uyaran tipi (e-sweep, MLS ve noise) ile ölçüm yapıldı; toplam 42 dürtü yanıtı elde edildi. Bu çalışmadaki akustik analizlerde MLS yanıtları ve Dirac yazıllmı kullanıldı: Akustik parametrelerden Çınlama süresi (RT), Ses Gücü (G), Erken Azalım Süresi (EDT), Belirginlik ( $\left.D_{50}\right)$, STI değerleri ve arka plan gürültü düzeyleri için ÇGDYY ile belirlenen sınır değerleri etüt edildi (2010c:tablo 9). Bu çalışmadaki tüm ölçümler ve analizler TS-EN-ISO standartlarına (2010a:2-17) uygun şekilde yapıldı.

\section{Ayrıntılı Ölçüm Sonuçları}

\section{Çınlama Süresi (RT)}

Sesin kapatıldığı andan itibaren $60 \mathrm{~dB}$ düşüşü için geçen süre hesaplanarak tiyatro salonlarındaki çınlama süresi için kabul gören 0,7-1,0 s (Barron, 2010:30), (dolu salonda ve $500-2000 \mathrm{~Hz}$ için öncelikli) değerleri gözetilir.

Konak Sahnesinin ölçümlerinde RT60 sonuçlarının (@500-2000Hz) boş salon için 0,90-1,42 saniye aralığında olduğu görülmektedir. Bu değerler yüksek olmakla birlikte salonun yüzde 80 dolu olduğu durum için yaklaşık 0,69-0,78 saniyeler düzeyine, yani uygun değerler aralığına gerileyeceği bilgisayar benzeşim yazııımı üzerinden hesaplanmaktadır. Analizlerde $250-1000 \mathrm{~Hz}$ bantlarındaki çınlamanın 1,42 sn. düzeylerine kadar çıktığı, $125-250 \mathrm{~Hz}$ frekanslarda bu değerlerin R1'de 1,67 sn ve R2'de 1,83 sn. düzeylerine ulaştı̆ı görülmektedir. Bu salonun tüm alıcı noktalarında çınlama sürelerinin kabul gören değerlerin üstünde olduğu anlaşılmaktadır.

\section{Ses Gücü (G)}

Ölçülen uyarı cevabına ait ses enerjisinin (karesi alınmış ve entegrali alınmış ses basıncı), ses kaynağından $10 \mathrm{~m}$ uzaklıktaki serbest ses alanında ölçülen cevaba logaritmik oranı analiz edildiğinde, S1 ve S2 kaynakları için, tüm alıcı noktalarındaki ses gücü düzeylerinin sonuçları şöyle değerlendirilmektedir.

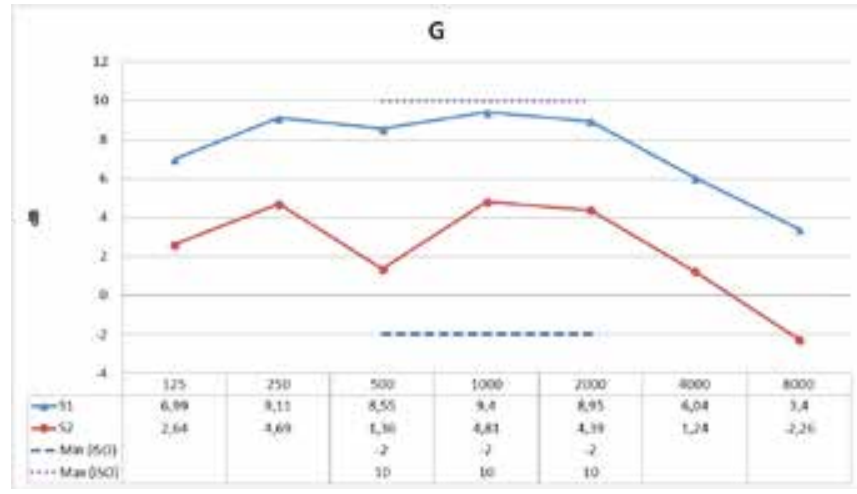

Şekil 3: S1 ve S2, tüm alıcı noktalarında ölçümlenen G ortalamaları

Buradan S1 ve S2 için ses gücü değerlerinin R1 hariç, kabul edilen sınırlar dâhilinde olduğu ancak bu sonuçların aslında çok da uygun olmadığı anlaşılır. R1 noktasındaki ses aşırı düzeyde sahne içi yutulmalarına işaret etmektedir. Ses düzeyi gücü, kaynaktan $10 \mathrm{~m}$ uzakta yaklaşık 2/3 oranında; başka bir deyişle milyonda birine kadar düşmektedir. R1 veS2 kaynak noktası aktif iken salonun en arkasında algılanan enerji düzeyi çok zayıftır. $125 \mathrm{~Hz}$ ve altı frekanslar için farklı lokasyonlarda sınır dışına taşan ve/ veya çok düşük değerler modal enerji yoğunlaşmaları, çökmeleri ve ortamdaki rezonansların varlığını işaret etmektedir.

\section{Erken Azalım Süresi (EDT)}

Burada, entegrali alınmış MLS uyarı cevabı eğrilerinin $0 \mathrm{~dB}$ ve $-10 \mathrm{~dB}$ arası en uygun doğrusal regresyon çizgisinden süresi hesaplanmaktadır. Standardın önerdiği değer aralığ 1-3 saniyedir (2010a:10). Bu salon için 1,75-2,15 saniye (Choi \& Fricke 2005; Kaak 2013;75'den) değer aralığı uygun büyüklük olarak kabul edilebilir.

Bilindiği gibi bu parametre çınlama süresinin öznel algılanışında önemli rol oynamaktadır. Bu değer salonun doluluğundan büyük ölçüde etkilenmez, ama performans salonlarında RT60 değerleri ile arasında $\pm 10 \%$ gibi bir ilişki bulunması da genel olarak kabul görmektedir. Bu salonda S1 için ölçülen EDT değerlerinin 0,97-1,21 saniye aralığında (@500-1000Hz) olduğu anlaşılmaktadır.

Ortalama EDT değeri 1,0 saniyedir. EDT mid ortalamaS1 S1 için $1,14 \mathrm{~s}$, S2 için ise 0.99 saniye seviyesindedir ve bunlar uygun değerler değildir. ISO sınır değerleri göz önüne alınsa bile S1 için bu sonuçlar uygun, S2 için uygun değildir. 


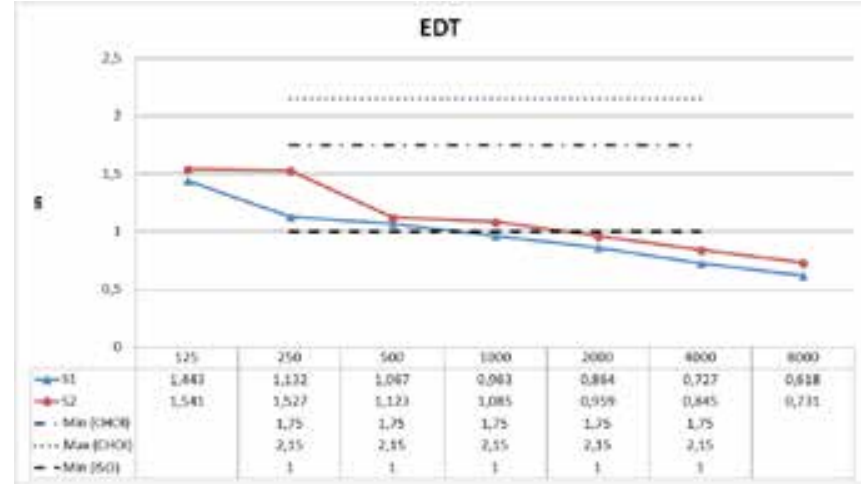

Şekil 4: S1 ve S2, tüm alıcı noktaları için ölçümlenen EDT ortalamaları

Yüksek EDT değerleri, konuşma anlaşılırlığının olumsuz yönde etkilendiğinin de bir göstergesidir. Sahne içi yüksek yutuculuk ve uygun olmayan fly loft (tavan çıkıntısı, ya da stage-house) formu, bu kaynak pozisyonunda özellikle düşük frekans değerlerinde sorun yaşanmasına neden olmaktadır.

\section{Belirginlik $\left(D_{50}\right)$}

Belirginlik durumu için erken ulaşan ses enerjisinin geç ulaşan ses enerjisine oranı analiz edilmektedir. Tiyatro salonlarında izleyiciler tarafından algılanan sesin netlik ve değerlerinin, oyunlardaki diyalogların anlaşılması, izleyicilerin yorulmadan izleyebilmesi ve mesajların doğru algılanabilmesi için yüksek olması yeğlenmektedir. Belirginlik değerinin kabul gören alt sınırı \%30 olmakla birlikte (2010a:10), tiyatro etkinlikleri için \%70' ler düzeyinde tutulması daha iyi olacaktır. Çok yüksek değerde bir sonuç ise ( 0.85 ve üstü) aşırı kuru, dar/küçük bir ortam etkisi yaratacağı için bu ortamda pek tercih edilmemelidir.

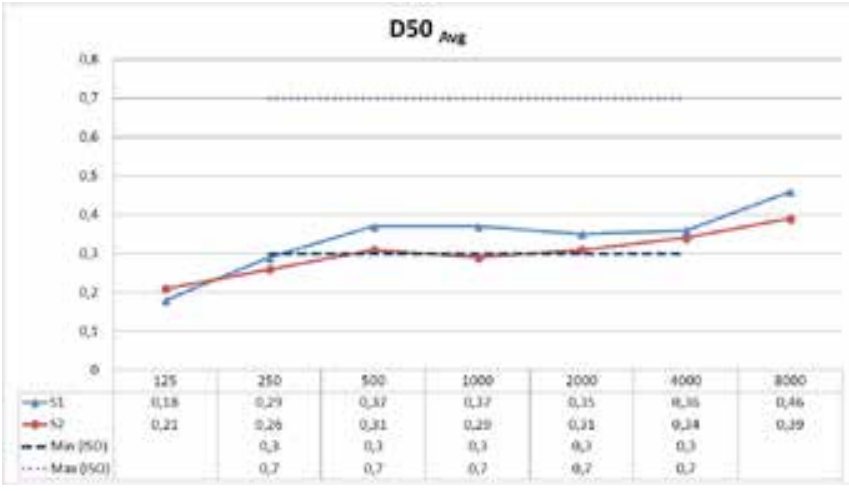

Şekil 5: S1 ve S2 tüm alıcı noktaları için D50 ortalamaları
S1 için, 10 m uzağa kadar olan alandaki alıcı nokta değerleri uygun olmakla birlikte (ortalama \% 56), bu mesafeden sonra (ortalama \% 12) algılamada büyük düşüş görülmektedir. S2 kaynak noktası için belirginlik \%30'dan daha düşüktür: ilk 5m'de ortalama \% 31, salonun kalan bölümlerinde ortalama \% 18'lik sonucuyla adeta bir "felaket" bölgesi oluşturur. Tüm alıcı noktalarında $500 \mathrm{~Hz}$ ve altındaki frekanslarda \%30'dan düşük değerler ile genel ortalamanın \%40 ve altında olması, burada kargaşa yaşandığının açık bir göstergesidir: Salonda $500 \mathrm{~Hz}$ altındaki frekanslarda, dolayısıyla kalın erkek sesleri ve diyaloglarda belirginlik düzeyi düşük olacaktır.

Kullanılan koltuk ve zemin malzemeleri, kontrolsüz yüksek ve düz tavan yapısı, fly loft tasarım ve karakteristikleri, salon-kişi hacmi oranları bu değer üzerinde etkilidir. Sonuç itibariyle belirginlik sonuçları genel ortalamaları ile hayli düşük olmakta, sahne kaynaklı yutulmalar, salon arka bölümünde oluşan rezonanslar ve denetimsiz çıplak yüzeyler konuşma anlaşılırlığını olumsuz yönde etkilemektedir.

\section{Ses İletim Göstergesi (STI)}

Ses iletimi, konuşmanın anlaşılabilirliği üzerindeki etkileri ve sinyalin gürültüye oranı ile doğrudan ilgilidir veortamda gürültü arttığı zaman gösterge değerleri de düşecektir.

Ölçüm sonuçlarına bakıldığında, salonun göstergesinin vasat-iyi arasında bir değer taşıdığı kolayca anlaşılır. $\mathrm{Bu}$ salon, kadın ve erkek seslerinin en düşük-en yüksek ortalamalarına göre, S1 için 0.57-0.64 (vasat-iyi), S2 için 0.41-0.57 (vasat) değerlerine sahiptir. Başka bir deyişle, sahne içi diyaloglarda S2 noktasındaki kaynağın anlaşılırlığı S1'e göre daha düşüktür, yani S2 noktasında duran bir oyuncunun anlaşılma şansı S1 noktasındaki rol arkadaşına göre daha zayıftır.

\section{Arka-plan gürültü düzeyi}

Salon havalandırması ve çevresel gürültü kaynaklarının etkilerini incelemek için, arka plan eşdeğer gürültü düzeyi değerleri 36,5 ve 39,6 dBA (havalandırma kapalı ve açık iken) olarak ölçülmektedir. Arka plan gürültü değeri 36,7 $\mathrm{dBA}$, havalandırma sistemlerinin arka plana olan etkisi ise 
0,2 dBA olarak hesaplanmaktadır. HVAC sisteminin arka plana olan etkisi yasal sınırlar dâhilindedir; sorun burada değildir. Asıl sorun, gürültü düzeyindeki genel yüksekliktir. Sonuçlar, BREEM HEA-13'de (Şan vd, 2013: Tablo 3) $30 \mathrm{dBA}$ olarak kabul edilen arka plan gürültü sınır değerine göre yüksektir ve sınır değerlere göre yaklaşık 4,5 kat daha büyük bir enerjinin varlığına işaret etmektedir. Gürültü ölçütü hedefleri açısından bakıldığında, NC-30 olması gereken en yüksek değer NC-34 olarak ölçülmektedir. Salonda, çevresel gürültü kaynaklarının olumsuz etkileri bulunmaktadır.

\section{Sonuç}

Konak Sahnesi, tarihi eser kapsamında olduğu için, bütünlüğü bozacak strüktürel değişikliklere izin verilmemektedir. Tavan yüksekliği $9 \mathrm{~m}$ gibi oldukça yüksek bir seviyededir. Taşıyıcı çatı elemanlarına yük vermeden, uygun akustik bitiş malzemeleri ile tavan yüksekliğinin düşürülmesi iyi bir çözüm olacaktır. Bu işlem sırasında tavandan gelen yansımaların kontrollü biçimde dağılımının yapılmasına azami özen gösterilmelidir. Bu doğrultuda yapılacak titizce hesaplanmış iyileştirme çalışmaları konuşmanın anlaşılabilirliği ve rezonans sorunlarına çözüm getirebilir.

Salonun arka bölümündeki istenmeyen akustik davranışları denetim altına alabilmek için uzmanlarca doğru hesaplanmış elektro-akustik projelerine ihtiyaç duyulmaktadır.

Tavanın yüksek oluşu, kişi başına düşen hacmin artmasına da neden olmaktadır. Kişi başı 7-9 $\mathrm{m}^{3}$ gibi bir hacim bu salon için çok yüksektir. Bir tiyatro salonunda tercihen 4-6 $\mathrm{m}^{3}$ değerleri aşılmamalıdır (Maekawa, 2011). Restorasyonda, zeminin bir bölümünde taban kotunun 50 $\mathrm{cm}$ aşağ ç çekilmesinin olumsuz akustik etkileri olduğu anlaşılmaktadır. Bu olumsuzlukları minimize edebilmek için tavanı, görüntüyü bozmayacak akustik elemanlar ile desteklemek uygun bir çözüm olabilir.ìkinci kattaki korumasız ses-1şık kontrol odası, kişi başına düşen hacmin $2,3 \mathrm{~m}^{3} \mathrm{ka}$ dar artmasına, akustik parametrelerin bozulmasına, algılamanın düşmesine neden olmaktadır. Bu sorun, bilgisayarlı benzeşim çalışmalarıyla çözülebilir niteliktedir.

Sahnenin mevcut formu, bir tiyatro sahnesi için seçilebilecek en kötü stage-house formudur. Sahnenin akustik açıdan daha etkin hale dönüştürülebilmesi adına, yapı tarihi bir niteliğe sahip olduğundan uygun bir çözüm önerilememektedir.

Salon iç gürültü değerleri, uluslararası normlar dışındadır ve hedef gürültü ölçütünün çok üstünde arka plan gürültü düzeylerinin oluştuğu anlaşılmaktadır. Kontrolsüz durumda bulunan kapı ve pencere detayları üzerinde kontrol çalışmalarının yapılması, bu noktalarda dış cephe itibariyle ilave strüktürel desteklerin sağlanması gerekmektedir.

Sahne sanatları için kullanılan bu tarihi yapının tiyatro etkinlikleri açısından uygunluğu dikkate alınacak olursa, salonda daha verimli bir ortam sağlaması, akustik kusurların önlenmesi, sanatçı ve izler kitlelerin iletişiminin artırılması, tarihi özellikteki bu kültürel varlığın tarihsel ve kültürel niteliğinin korunması için, uzmanlar tarafından akustik ve elektro-akustik uygulama projeleri hazırlanıp uygulanması, kabul edilebilir normlara oturtulması gerekmektedir.

\section{Notlar}

1 Brüel and Kjäer 2250: serial\# 3004459

Brüel and Kjäer 4292-L: serial\# 024003

Brüel and Kjäer 2734: serial\# 031007

DIRAC 6.0.5381.1981 (Type 7841, acoustics-engineering)

$18 \mathrm{i} 20$ (Focusrite Scarlet): serial\# S563348014335

Dawe Instruments: serial\# 2/01920316

\section{Kaynakça}

(2010a). TS EN ISO 3382-1. Odaların Akustik Parametrelerinin Ölçülmesi. Bölüm 1: Gösteri Mekânları. (ISO 33821.2009). Türk Standartları Enstitüsü, Ankara

(2010b). TS EN ISO 3382-2. Akustik, Odalarin Akustik Parametrelerinin Ölçülmesi. Bölüm 2: Sıradan Odalarda Çınlama Süresi (ISO 3382-2. 2008). Türk Standartları Enstitüsü, Ankara

(2010c). Çevresel Gürültünün Değerlendirilmesi ve Yönetimi Yönetmeliği. Çevre ve Orman Bakanlığı, Ankara. Resmi Gazete; 4 Haziran 2010, Cuma, sayı: 27601

(2014). Devlet Tiyatroları Genel Müdürlüğü 2013 Yılı Faaliyet Raporu. DT Genel Müdürlüğü Strateji Geliştirme Müdürlüğü. Ankara, p.42 
Barron, M. (1993). Auditorium Acoustics and Architectural design. E\& FN Spon, and imprint of Chapman \& Hall 2

Barron, M. (2010). Auditorium Acoustics And Architectural Design. USA: Spon Press. ISBN 0-203-87422-6, p.30

Beranek, L. L. (1988). Acoustical Measurements Revised ed., USA: Acoustical Society of America.

Beranek, L.L. (1996), Concert and Opera Halls: How They Sound 1st ed., New York: Acoustical Society of America.

Choi, Y.J., Fricke, F.R. (2005). Evaluation of the relative acoustic performance of two auditoria using measurements and auralization, Acta Acustica united with Acustica (91), pp. 1051-1062

Gade, A.C. (1989). Investigations $f$ Musicians' Room acoustic Conditions in Concert Halls. Part I: Methods and Laboratory experiments; Part II: field experiments and synthesis of results. Acustica (69): 194-195; 249-262.

Houtgast, T., Steeneken, H.J.M. (1985). The Modulation Transfer Function in Room Acoustics, Brüel\&Kjaer Technical Review 3, Denmark, No. 3: 3-12

Kaak, Stefan. (2013). Zur Standardisierung der Akustik musikalischer Aufführungsräume. Yayınlanmamış Master Tezi, Institut für Sprache und Kommunikation, Technische Univertität Berlin, Deutschland

Maekawa, Z., \& Rindel, J. H. \& Lord, P. (2011). Environmental and architectural acoustics. Spon Press, Version. s.234

Şan, B., Ökten, G., Bayazıt, N.T. (2011). Yeşil Bina Sertifikasyon Sistemlerinin Akustik Açıdan İncelenmesi ve ülkemizdeki Durumun Değerlendirilmesi. 9. Ulusal Akustik Kongresi, ODTü, 26-27 Mayıs, Ankara

Thiele, R. (1953). Richtungsverteilung und Zeitfolge der Schallrückwürfe in Räumen. Acta Acustica United with Acustica, 3 (Supplement 2), p.291-302.

Türk, E., Can, Z. Y., Özçevik, A., (2011). İstanbul'daki Salonların Akustik Açıdan İncelenmesi, 9. Ulusal Akustik Kongresi, 26-27 Mayıs, 2011, s.10

\section{İnternet Kaynakları}

Oğuz, Mustafa (2009). İzmir'de Süper Bir Devlet Tiyatrosu. http://www. hurriyet.com.tr/ ege/12455933.asp (Erişim tarihi: 11.08.2015)
Şan, B., Ökten, G., Bayazıt, N.T. (2011). Yeşil Bina Sertifikasyon Sistemlerinin Akustik Açıdan İncelenmesi ve Ülkemizdeki Durumun Değerlendirilmesi. 9. Ulusal Akustik Kongresi, ODTü Kültür ve Kongre Merkezi, Ankara. Tablo 3

Yazıcı, Cengiz (2010). Türk Ocağı’ndan Devlet Tiyatrosu'na. http://www. izmirdergisi.com/site/index.php?option $=$ com_content $\&$ view $=$ article $\& i d=98 \&$ Itemid=374\&lang $=\operatorname{tr}($ Erişim tarihi: 11.08 .2015$)$

Kültür (2015). İllerde Faaliyette Olan Kültür Merkezleri. http:// yigm.kulturturizm. gov.tr/TR,9787/illerde-faaliyetteolan-kultur-merkezleri-50-adet.html (Erişim tarihi: 12.08.2015)

\section{Görsel Kaynaklar}

Şekil 1: İzmir Rölöve ve Anıtlar Müdürlüğü tarafından hazırlanan rölöve planı (üstte), kaynak (S1 ve S2) ve alıcı (R1-R7) noktaları, A-A kesiti (altta).

Şekil 2: Ölçme sistemi sinyal akış uygulama şeması.

Şekil 3: S1 ve S2, tüm alıcı noktalarında ölçümlenen G ortalamaları.

Şekil 4: S1 ve S2, tüm alıcı noktaları için ölçümlenen EDT ortalamaları.

Şekil 5: S1 ve S2, tüm alıcı noktaları için D50 ortalamaları. 